\title{
Anagen Effluvium after Neurointerventional Radiation: Trichoscopy as a Diagnostic Ally
}

\author{
María D. Guerrero-Putz ${ }^{a} \quad$ Ana C. Flores-Dominguez ${ }^{a}$ \\ Rodrigo J. Castillo-de la Garza ${ }^{a}$ Jose A. Figueroa-Sanchez ${ }^{b}$ Antonella Tosti ${ }^{c}$ \\ Verónica Garza-Rodríguez ${ }^{\mathrm{a}}$ \\ aUniversidad Autónoma de Nuevo León, Facultad de Medicina, Servicio de Dermatología Hospital Universitario

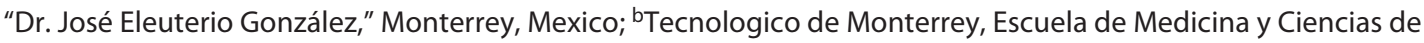 \\ la Salud, Monterrey, Mexico; 'Dr. Phillip Frost Department of Dermatology and Cutaneous Surgery, University of \\ Miami Miller School of Medicine, Miami, FL, USA
}

\section{Keywords}

Anagen effluvium · Trichoscopy · Neurointerventional radiation

\begin{abstract}
Minimally invasive procedures for vascular brain lesions are being performed more frequently. Radiation exposure caused by endovascular embolization of cerebral aneurysms may give rise to nonscarring scalp alopecia located in the treated area. Clinical and trichoscopic features of this type of alopecia are similar to alopecia areata (AA). Herein, we performed a comprehensive review to describe the clinical and trichoscopic characteristics of radiation-induced anagen effluvium. Predominant trichoscopic findings include black dots, yellow dots, short vellus hairs, and absence of exclamation marks hairs. It is important to consider this diagnosis in patients who have recently undergone such procedures that can easily be misdiagnosed as AA.
\end{abstract}

\section{Introduction}

Anagen effluvium is a nonscarring alopecia caused by various insults, most commonly associated with chemotherapeutic agents. Approximately $90 \%$ of scalp hairs are anagen follicles, which is the hair growth phase of active division and proliferation that lasts from 2 to 6 years [1]. Anagen follicles are very sensitive to high doses of radiation, which causes damage in the actively dividing cells [ 1 , 2]. Unlike chemotherapy or radiotherapy induced anagen effluvium, intracranial endovascular procedures produce a well-demarcated alopecic patch consistent with the treatment area [3] (Fig. 1).

Radiation-induced anagen effluvium after neurointerventional procedures has been reported with increasing frequency. Nonetheless, its clinical characteristics and trichoscopic features are nonspecific, thus further research could aid in the diagnosis. Since minimally invasive procedures with radiation are performed more frequently in the field of neurointerventional surgery, dermatologists should include radiation-induced temporary alopecia [4] in the differential diagnosis of nonscarring alopecias. karger@karger.com www.karger.com/sad (c) 2021 S. Karger AG, Basel

Karger'
Correspondence to:

Verónica Garza-Rodríguez, verogarzardz@ hotmail.com 

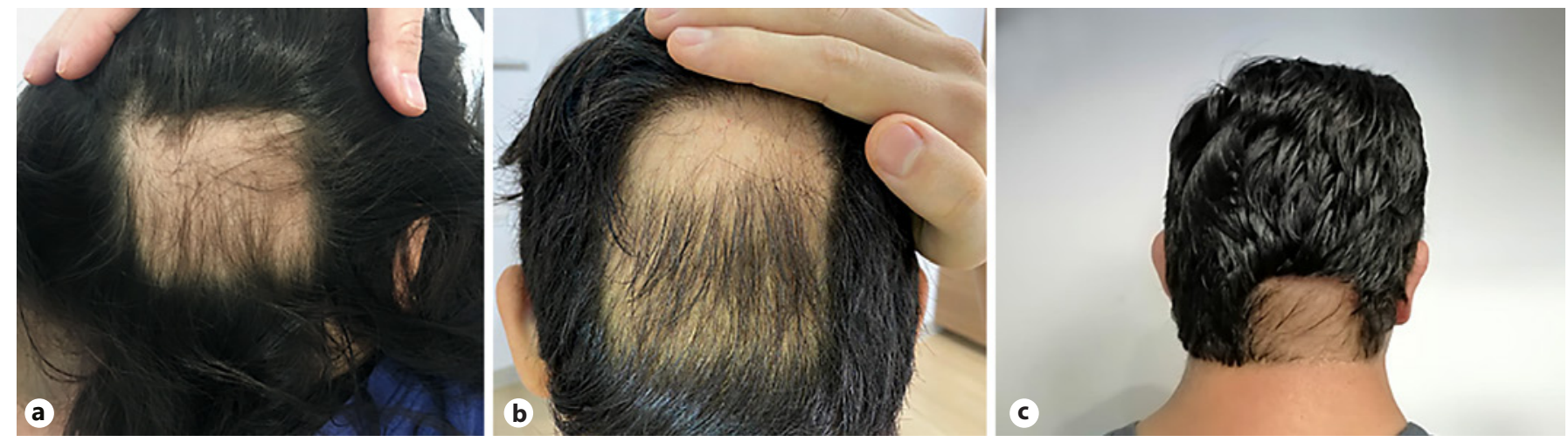

Fig. 1. a Four-year-old female patient with rectangular pseudo-alopecic patch in the temporal occipital scalp due to endovascular embolization of carotid-cavernous fistulae secondary to trauma. b Nineteen-year-old male patient with rectangular pseudo-alopecic patch in the occipital scalp 2 weeks after second session (2/3) for endovascular stent placement. c Forty-nine-year-old male patient with pseudo-alopecic patch on the occipital scalp 2 weeks after undergoing cerebral aneurysm embolization.
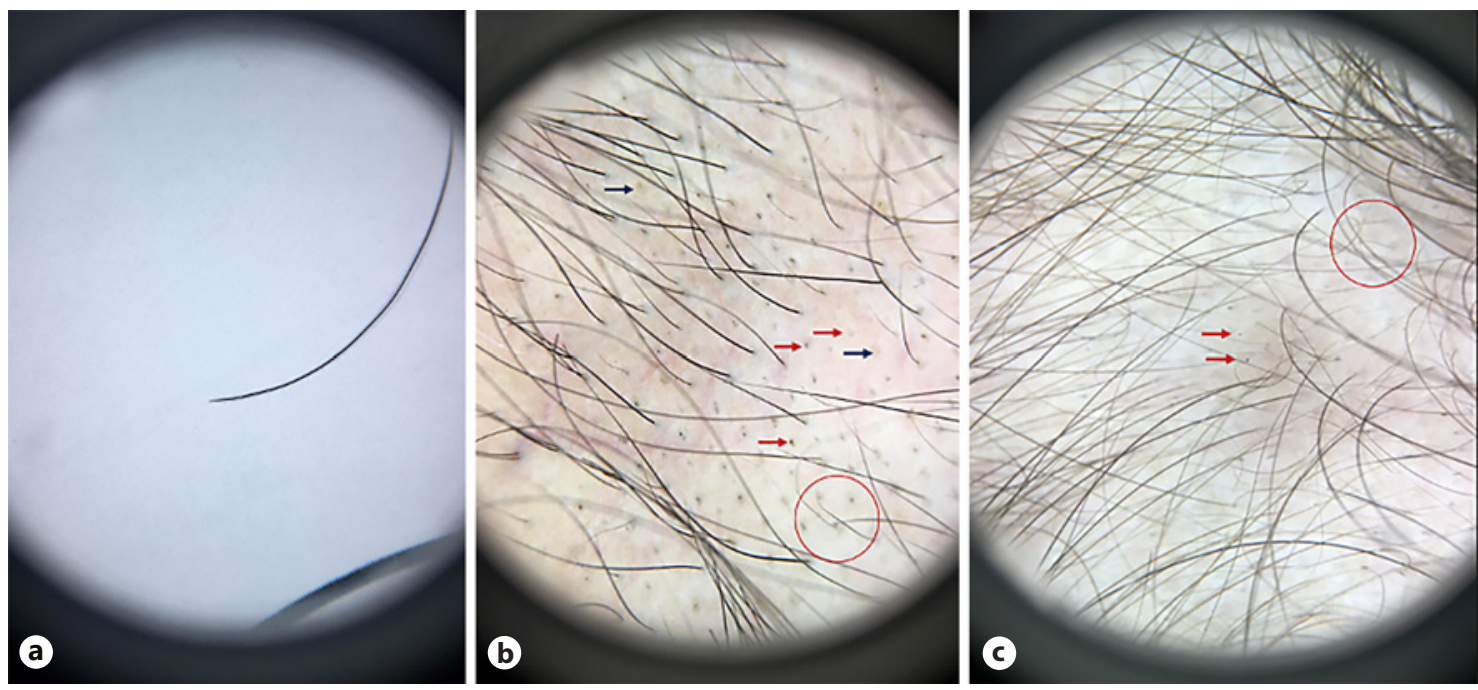

Fig. 2. a Anagen hair. b, c Red arrows: black dots; blue arrows: yellow dots; red circles: short vellus hairs.

Herein, we conducted a comprehensive search of current literature from PubMed and SCOPUS search engines, including case series and case reports that described trichoscopic findings of patients with radiation-induced temporary alopecia. A total of 25 research outputs were found, including textbooks, book chapters, case reports, case series, original articles, and reviews. We then decided to include 8 articles describing neurointerventional radiation procedures, as well as 3 personal cases from our clinic.

Current literature regarding clinical and trichoscopic findings in patients who developed an alopecic patch after neurointerventional radiation exposure, including our cases is shown in Table 1. A total of 22 cases including our 3 cases have been reported on the literature up to this date. Demographic and clinical characteristics are shown in Table 2. Women represent $63.6 \%$ of cases, men $36.4 \%$, with a wide age-group, from 4 - to 70 -year-old patients, $63.6 \%$ between 20 and 50 years, $9 \%<20$ years, and $36 \%$ 50-year-old patients or older. The most common trichoscopic findings reported (shown in Table 3; Fig. 2) were yellow dots $(50 \%)$, black dots (50\%), short vellus hairs (41\%), and absence of exclamation mark hairs (23\%); additional trichoscopic findings were coiled hairs, peripilar sign, lack of terminal hairs, broken hairs, dystrophic hair roots, white dots and blue-gray dots in a tar- 


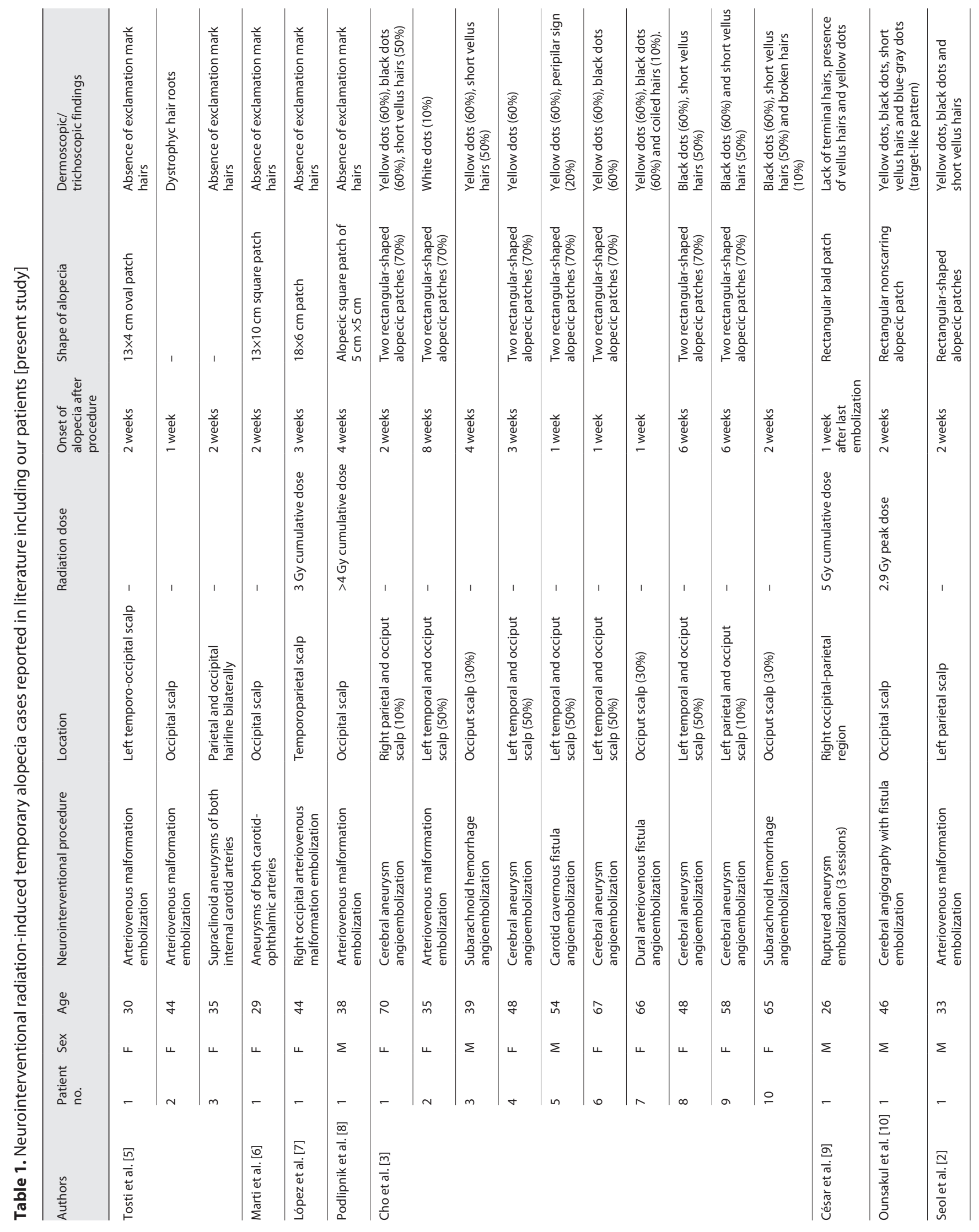




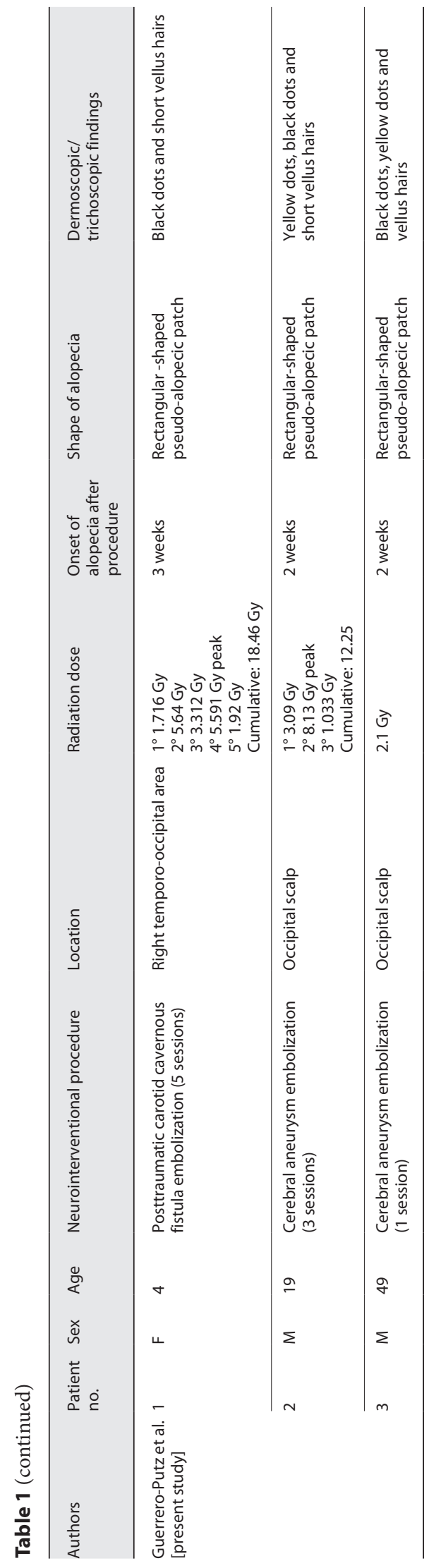

Trichoscopy in Anagen Effluvium Induced by Neurointerventional Radiation
Table 2. Demographic and clinical characteristics

\begin{tabular}{ll}
\hline Characteristics & $n(\%)$ \\
\hline Patients & $22(100)$ \\
Gender & \\
Male & $8(36.4)$ \\
Female & $14(63.6)$ \\
Age range & $4-70$ \\
$\quad$ <20 years & $2(9)$ \\
$20-50$ years & $14(63.6)$ \\
$>50$ years & $6(36.4)$ \\
Shape of alopecia & \\
Rectangular & $13(59)$ \\
Square & $3(13.6)$ \\
Oval & $1(4.5)$ \\
Onset of alopecia & \\
1 week & $5(22.7)$ \\
2 weeks & $9(40.9)$ \\
3 weeks & $3(13.6)$ \\
4 weeks & $2(9)$ \\
6 weeks & $2(9)$ \\
8 weeks & $1(4.5)$ \\
\hline
\end{tabular}

Table 3. Trichoscopic findings

\begin{tabular}{ll}
\hline Trichoscopic findings & $n(\%)$ \\
\hline Black dots & $11(50)$ \\
Yellow dots & $11(50)$ \\
Short vellus hairs & $9(41)$ \\
Absence of exclamation mark hairs & $5(23)$ \\
Vellus hairs & $2(9)$ \\
Peripilar sign & $1(4.5)$ \\
Dystrophic hair roots & $1(4.5)$ \\
White dots & $1(4.5)$ \\
Broken hairs & $1(4.5)$ \\
Coiled hairs & $1(4.5)$ \\
\hline
\end{tabular}

get-like pattern $[2,3,9,10]$. The location of the alopecic patch corresponded to the area that received radiation during the endovascular procedure (Fig. 3). The time from the procedure to the onset of alopecia (Fig. 4) ranged between 1 and 8 weeks, with an average of 2 weeks. The radiation dose reached was not reported consistently, recorded doses ranged from a peak single dose of $2.9 \mathrm{~Gy}$ [10] to a cumulative dose of $18.46 \mathrm{~Gy}$ in one of our cases (Table 1, Guerrero-Putz et al. [present study] case 1).

Alopecia areata (AA) is one of the most important differential diagnoses in this clinical setting. Trichoscopic characteristics are similar between both entities. Wáskiel et al. [11] performed a systematic review in 2018 to up- 
3

Fig. 3. Shape of alopecic patch.

Fig. 4. Onset of alopecia after neurointerventional radiation.
4

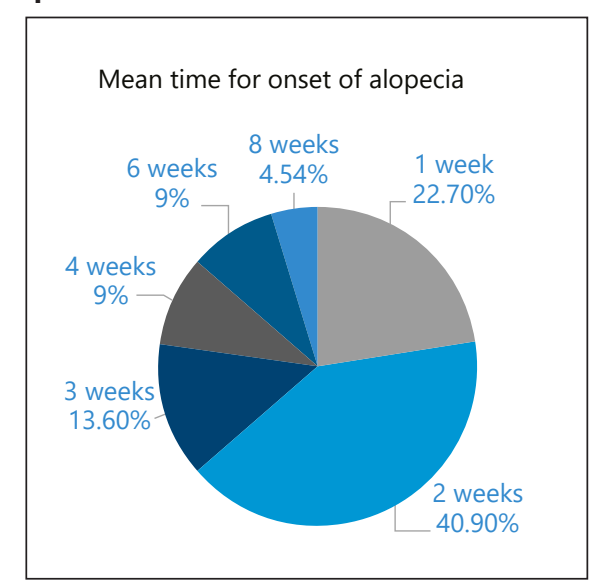

date trichoscopic findings in $\mathrm{AA}$, the most frequent trichoscopic features were the following, in order of frequency: yellow dots, black dots, exclamation mark hairs, tapered hairs, broken hairs, short vellus hairs, upright regrowing hairs, and Pohl-Pinkus constrictions. In patients presenting anagen effluvium after neurointerventional radiation, we found that the most frequent features are similar to those found in AA, being yellow dots and black dots the most frequent, followed by short vellus hairs. An important feature of AA that has not been reported in radiation-induced temporary alopecia is exclamation mark hairs, which could be a specific marker for the differential diagnosis.

Histopathology findings have been reported in few cases. Histopathology features include increased numbers of catagen and telogen hairs without perifollicular infiltration, with no peribulbar inflammatory cell infiltrate $[3,10]$. Medical history in patients with radiationinduced temporary alopecia often shows that they are undergoing stressful situations and induce doctors to think to "stress induced" AA.

Patients usually do not require treatment, it is important to reassure them that hair regrowth will occur, topical 5\% minoxidil BID and intralesional triamcinolone have been utilized $[2,10]$. Hair regrowth onset ranges from 2 to 24 weeks after the procedure [5-8, 12-14] up until 12 months after [9].

\section{Conclusion}

Hair loss is a known side effect of radiation treatments such as radiotherapy and endovascular procedures. High doses of ionizing radiation, as used for radiotherapy, cause scarring alopecia due to stem cell damage [15]. Low doses as utilized in neurointerventional procedures cause temporary alopecia due to anagen effluvium.

As dermatologists, it is important to think of radiation-induced temporary alopecia in patients who develop patchy hair loss after neurointerventional procedures. Physicians that perform such procedures should be able to anticipate these outcomes among other complications associated with radiation injury and monitor patients throughout the treatment course [16]. Further research including trichoscopic features may help in making the correct diagnosis in a timely manner, avoiding unnecessary treatment as well as to provide a prognosis.

\section{Statement of Ethics}

Written informed consent was obtained from the patient for publication of any accompanying images.

\section{Conflict of Interest Statement}

The authors have no conflicts of interest to declare.

\section{Funding Sources}

The authors have no funding sources.

\section{Author Contributions}

Dr. Guerrero-Putz and Dr. Garza-Rodriguez contributed to the design, drafting of the work, and interpretation of data. Dr. FloresDominguez contributed to data analysis and interpretation of data. Dr. Tosti contributed to drafting the work and design. Dr. Castillode la Garza contributed to literature and data analysis. Dr. Figueroa-Sanchez contributed to drafting of the work and interpretation of data. 


\section{References}

1 Saleh D, Naddereddin A, Cook C. Anagen effluvium. In: StatPearls [Internet]. Treasure Island (FL): StatPearls Publishing; 2021 Jan [Updated 2020 Aug 12].

2 Seol JE, Kim DH, Park SH, Cho GJ, Kim H. Three cases of radiation-induced temporary alopecia with hair microscopic examination: "coudability hair" might not be specific for alopecia areata. Int J Trichology. 2018;10(1): 40-3.

3 Cho S, Choi MJ, Lee JS, Zheng Z, Kim DY. Dermoscopic findings in radiation-induced alopecia after angioembolization. Dermatology. 2014;229(2):141-5.

4 Vaccaro M, Guarneri F, Brianti P, Cannavò SP. Temporary radiation-induced alopecia after embolization of a cerebral arteriovenous malformation. Clin Exp Dermatol. 2015; 40(1):88-90.

5 Tosti A, Piraccini BM, Alagna G. Temporary hair loss simulating alopecia areata after endovascular surgery of cerebral arteriovenous malformations: a report of 3 cases. Arch Dermatol. 1999;135(12):1555-6.
6 Marti N, Lopez V, Pereda C, Martin JM, Montesinos E, Jorda E. Radiation-induced temporary alopecia after embolization of cerebral aneurysms. Dermatol Online J. 2008;14(7): 19.

7 López V, López I, Ricart JM. Temporary alopecia after embolization of an arteriovenous malformation. Dermatol Online J. 2012; 18(9):14.

8 Podlipnik S, Giavedoni P, San-Román L, Ferrando J. Square alopecia: a new type of transient alopecia of the scalp following fluoroscopically endovascular embolization. Int $\mathrm{J}$ Trichology. 2013;5(4):201-3.

9 César A, Baudrier T, Mota A, Azevedo F. Geometric alopecia after embolization of a ruptured aneurysm. Actas Dermosifiliogr. 2015; 106(2):148-50.

10 Ounsakul V, Iamsumang W, Suchonwanit P. Radiation-induced alopecia after endovascular embolization under fluoroscopy. Case Rep Dermatol Med. 2016;2016:8202469.

11 Waśkiel A, Rakowska A, Sikora M, Olszewska M, Rudnicka L. Trichoscopy of alopecia areata: an update. J Dermatol. 2018;45(6):692700 .
12 Wen CS, Lin SM, Chen Y, Chen JC, Wang $\mathrm{YH}$, Tseng SH. Radiation-induced temporary alopecia after embolization of cerebral arteriovenous malformations. Clin Neurol Neurosurg. 2003;105(3):215-7.

13 Nannapaneni R, Behari S, Mendelow D, Gholkar A. Temporary alopecia after subarachnoid haemorrhage. J Clin Neurosci. 2007;14(2):157-61.

14 Verma S, Srinivas C, Thomas M. Radiationinduced temporary alopecia after embolization of cerebral aneurysm. Indian J Dermatol. 2014;59(6):633.

15 Nanashima N, Ito K, Ishikawa T, Nakano M, Nakamura T. Damage of hair follicle stem cells and alteration of keratin expression in external radiation-induced acute alopecia. Int J Mol Med. 2012;30(3):579-84.

16 Balter S, Hopewell JW, Miller DL, Wagner LK, Zelefsky MJ. Fluoroscopically guided interventional procedures: a review of radiation effects on patients' skin and hair. Radiology. 2010;254(2):326-41. 